\title{
ESTUDO DE ISOLANTE TÉRMICO CONFECCIONADO A PARTIR DE MATERIAIS NANOCOMPÓSITOS DE MATRIZ CERÂMICA AGREGADO DE RESÍDUOS INDUSTRIAIS
}

\author{
Rafael Martins da Silva ${ }^{1}$ \\ Adriane Lawisch Rodriguez, ${ }^{2}$ \\ Diosnel Antonio Rodriguez Lopez ${ }^{3}$ \\ Claudia Mendes Mahlmann ${ }^{4}$
}

\begin{abstract}
RESUMO
Através da constante busca de novos materiais com características físico-químicas eficientes que unam viabilidade econômica e ambiental, o presente trabalho objetivou a confecção de um material compósito constituído por uma matriz cerâmica agregada de resíduos das indústrias de vidro e fumo, com a finalidade de produção de um isolante térmico para um sistema de aquecimento solar de água. $\mathrm{O}$ estudo foi realizado em três etapas: caracterização dos materiais, confecção dos corpos de prova, ensaios de resistência mecânica e eficiência térmica. Foram desenvolvidos corpos de prova de matriz (100\% em massa de argila) e os corpos de prova com substituição de $25 \%$ de massa pelos resíduos, sendo eles $20 \%$ de pó de vidro e $5 \%$ de pó de fumo, para a análise comparativa das novas propriedades adquiridas. Os resultados obtidos revelaram um aumento de 57\% na eficiência mecânica (resistência) no material compósito, obtendo também características eficientes quanto ao isolamento térmico.
\end{abstract}

Palavras-chave: Cerâmica. Compósito. Isolante. Resíduos.

\begin{abstract}
Through constant search for new materials with efficient physicochemical characteristics that unite economic and environmental feasibility, this study aimed to the preparation of a composite material consisting of a ceramic matrix aggregated of waste of glass and tobacco industries, with purpose of producing a thermal insulator for a solar water heating. The study was conducted in three steps: characterization of materials, preparation of specimens, tests of mechanical strength and thermal efficiency. Samples of matrix (100\% of clay) and the specimens were developed with replacement of $25 \%$ of the waste mass, namely $20 \%$ of glass powder and $5 \%$ powdered tobacco, for comparative analysis the new property acquired. The results showed an increase of $57 \%$ mechanical efficiency (resistance) in the composite material, also getting efficient features as thermal insulation.
\end{abstract}

Keywords: Ceramic. Composite. Insulation. Waste.

\footnotetext{
1 Aluno do Curso de Engenharia Ambiental da Universidade de Santa Cruz do Sul - UNISC. <rafaelmartins26@yahoo.com.br>

2 Professora do Departamento Engenharia, Arquitetura e Ciências Agrárias na Universidade de Santa Cruz do Sul - UNISC. 〈adriane@ unisc.br>

${ }_{3}^{3}$ Professor do Departamento Engenharia, Arquitetura e Ciências Agrárias na Universidade de Santa Cruz do Sul - UNISC.<diosnel@unisc.br>

${ }^{4}$ Professora do Departamento de Química e Física na Universidade de Santa Cruz do Sul - UNISC. <mclaudia@unisc.br>
} 


\section{INTRODUÇÃO}

A energia solar é a fonte menos poluente e menos finita conhecida até o momento, porém nunca foi aproveitada de forma eficiente. As fontes convencionais usualmente utilizadas para o abastecimento energético já apresentam indícios de extinção, com isso intensificou-se a busca de fontes com grandes potenciais energéticos que não agridam em demasia o meio ambiente, tal como a energia solar.

Através desta prerrogativa, entende-se a necessidade de tecnologias que visem não somente o uso desta fonte de energia de forma eficiente como também o seu armazenamento, este que, por sua vez, representa um grande desafio econômico, comparado a outros tipos de energias.

Ainda em consequência da expansão tecnológica e industrial, motivada pela busca crescente do conforto e de bens de consumo, problemas relacionados à matriz energética, tais como apagões por sobrecarga e altas emissões de poluentes atmosféricos são cada vez mais comuns. Assim como, porém não menos preocupante, os problemas ligados aos resíduos sólidos industriais que, devido ao grande volume, são destinados a aterros sanitários e/ou lixões, que por sua vez ocupam grandes áreas gerando graves impactos ambientas. Em consequência destes fatos, nota-se a importância da busca de tecnologias que visem não somente a obtenção de energias renováveis e ambientalmente viáveis, mas também a incorporação e o reaproveitamento de resíduos as quais reduzam os impactos ambientais relacionados à produção, contribuam para a diversificação/fabricação de produtos e diminuam os custos finais ligados à sua confecção.

Segundo Menezes (2002), produtos de cerâmica vermelha representam uma área de grande potencial para incorporação de resíduos. Este fato está relacionado a características como grande volume de produção, o qual utiliza grande quantidade de matérias primas; longa vida útil destes produtos; capacidade de encapsulamento dos resíduos incorporados; tolerância a variações de composição de suas matérias-primas; viabilidade de agregação de quantidades consideráveis de resíduos. Através destas características, assim como o baixo coeficiente de transferência térmica, bom índice de resistência mecânica e baixo custo, tecnologias que empregam a utilização de nanocompósitos em matriz cerâmica são promissores. Ainda segundo Askeland (2008), materiais cerâmicos são compostos de estruturas cristalinas, mono ou policristalina. São compostos por elementos metálicos e não metálicos, encontrados principalmente na forma de óxidos, silicatos, carbonetos e nitretos. Possuem características 
como: isolamento elétrico, baixo coeficiente térmico, resistência à abrasão, resistência a altas temperaturas, alta dureza, fragilidade, sendo que, os mais conhecidos estão na forma de vidros, cimento, materiais refratários, argilas e semicondutores.

Os materiais compósitos surgiram pela necessidade de combinar propriedades incompatíveis, como por exemplo, resistência mecânica e tenacidade (SANTIAGO et al, 2007).

Os compósitos podem ser definidos como materiais constituídos de duas ou mais fases, insolúveis entre si, denominadas matriz e reforço. A fase denominada matriz pode ser um material polimérico, cerâmico ou metálico. Já o reforço é considerado como um material que melhore ou crie propriedades físicas ou químicas para o produto final. (DANIEL e ISHAI, 2006). Ainda aqueles que possuam partículas na faixa de 1 a 100 nm, são conhecidos como nanocompósitos. Estes são constituídos de materiais que tenham como fase dispersa (no presente projeto, pó de vidro e pó de fumo) granulometria nanométrica. Segundo Auffan (2009), as nanopartículas tem propriedades e características não compartilhadas por partículas fora dessa escala.

O vidro é classificado por ser um sólido amorfo, não cristalino, referido como líquido super resfriado. Ainda segundo Doremus (1973), vidro é um produto inorgânico, proveniente de uma fusão, enrijecido pelo resfriamento, sem cristalização. Entre suas principais características estão: reciclabilidade, transparência, dureza, isolante dielétrico, baixa condutividade térmica, durabilidade.

A incorporação de resíduo de vidro a diferentes matrizes tem sido vastamente pesquisada, uma das alternativas é a agregação deste rejeito a produtos fabricados em base cerâmica, opção com alta viabilidade, pois há compatibilidade entre a composição química destes produtos e a do vidro. Ainda segundo Morelli e Baldo (2003), a introdução de vidro em massas cerâmicas demonstrou que pode haver diminuição no patamar de queima das peças, melhora na resistência mecânica e diminuição da absorbância de água.

Materiais orgânicos em pequenas porcentagens de massa auxiliam na conformação dos materiais compósitos agregando resistência mecânica, fato este confirmado por Soares (2003), onde afirma que, a serragem de fumo pode ser adicionada à massa cerâmica para a produção de materiais cerâmicos, sendo as percentagens de 5 a $15 \%$ as mais viáveis tecnicamente. Salienta-se que a região de Santa Cruz do Sul é uma das maiores produtoras de fumo do mundo, conta com um considerável número de indústrias que a beneficiam, as quais geram grandes volumes de pó de fumo, resíduo este que atrai preocupação por parte destas 
empresas e órgãos ambientais pelo já citado excessivo volume e pela falta de opções de como o gerenciar. Através desta problemática, a incorporação deste resíduo em materiais compósitos se faz promissora.

Com este enfoque, buscou-se à incorporação de nanomateriais oriundos de resíduos de processos industriais em matriz cerâmica, para posterior confecção de um isolante térmico para o reservatório (boiler) de um sistema de aquecimento solar de água, objetivando índices de isolamento próximos ou iguais aos comumente utilizados, mantendo-se competitividade econômica associado à incorporação de resíduos na fabricação de novos materiais.

\section{METODOLOGIA}

O fluxograma da figura XX, apresenta a metodologia de preparação e adição dos resíduos na massa cerâmica, bem como os ensaios de caracterização dos materiais.

Figura 1: Metodologia de preparação e caracterização dos corpos de prova

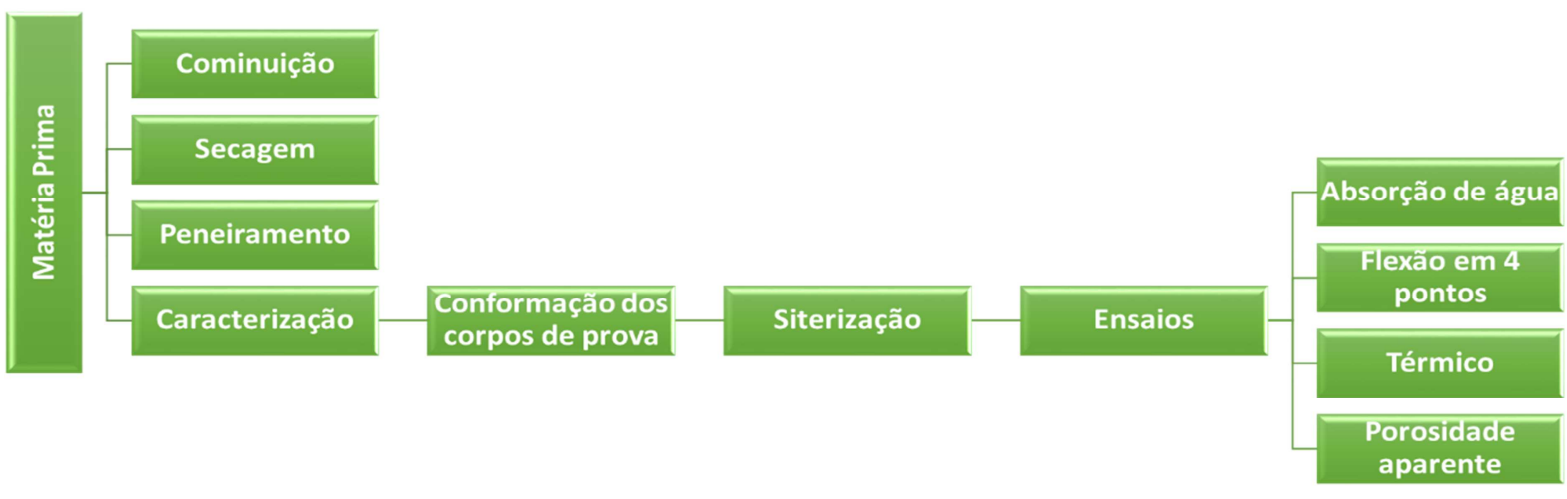

\subsection{Preparação dos materiais}

Inicialmente foram realizados os processos de desumidificação e cominuição da cerâmica vermelha (matriz cerâmica), pó de fumo e pó de vidro (reforços). Para a etapa de desumidificação os resíduos, assim como a cerâmica vermelha, foram dispostos à temperatura ambiente por 8 horas (período na presença do sol), após foram colocados em estufa a $50^{\circ} \mathrm{C}$ durante um período de 24 horas, com o objetivo de retirar a umidade. Após esse período, foram realizadas etapas de cominuição em um moinho britador e posteriormente em um moinho de bolas.

$\mathrm{Na}$ caracterização granulométrica, iniciada em seguida a fase de cominuição, utilizou-se um conjunto de peneiras a fim que se obtivesse apenas partículas passantes na 
peneira de 80 mesh, com o intuito de melhor conformação do material. Para tal, utilizou-se um tempo de 15 min para o peneiramento.

\subsection{Confecção dos corpos de prova}

O processo de confecção dos corpos de prova foi realizado em 3 etapas, sendo elas:

- Realização das formulações: realizou-se misturas com teores diferentes da matriz e reforços, assim como também formulações que levassem apenas um dos reforços. Estas formulações foram realizadas em porcentagem de $\mathrm{m} / \mathrm{m}$, sendo elas: $75 \%$ cerâmica vermelha, $20 \%$ pó de vidro e $5 \%$ pó de fumo (formulação escolhida para o ensaio térmico final); $80 \%$ cerâmica vermelha e $20 \%$ pó de vidro; $90 \%$ cerâmica vermelha e $10 \%$ pó de vidro; $100 \%$ cerâmica vermelha.

- Prensagem: foram dispostas as formulações em um molde com área superficial de 6 $\mathrm{cm}$ x $12 \mathrm{~cm}$. Estes foram prensados a 4 toneladas em uma prensa hidráulica pelo tempo de 10 segundos.

- Sinterização: os corpos de prova, depois de prensados, foram para uma estufa a 50 ${ }^{\circ} \mathrm{C}$ por 24 horas, para posterior queima em um forno elétrico a um patamar de $1000{ }^{\circ} \mathrm{C}$ por 8 horas, em uma taxa de aquecimento de $150{ }^{\circ} \mathrm{C} /$ hora em um tempo de $6 \mathrm{~h} 40 \mathrm{~min}$.

\subsection{Caracterização mecânica e física dos corpos de prova}

Para caracterização dos corpos de prova, foram realizados ensaios de flexão em 4 pontos, absorção de água, porosidade aparente. Os corpos cerâmicos, após a sinterização, foram caracterizados quanto à resistência mecânica por flexão a quatro pontos. Este ensaio é baseado na norma técnica ASTM C - 133/97 e foi realizado em uma máquina de ensaios universal ATS modelo 1105 C. Ainda após a queima, foi realizado o ensaio de absorção de água. Este representa o aumento de peso do material úmido em relação ao seco. A obtenção do peso úmido foi realizada pela imersão dos corpos cerâmicos em água em um período de 24h. Após este período, com a ajuda de um papel toalha foi retirada a água superficial e novamente os corpos de prova foram pesados. Através da relação entre o peso depois da imersão e após a secagem, foram feitos cálculos conforme normas NBR 15270-3 e NBR 15310:2009.

Para a realização do ensaio de porosidade aparente, os corpos cerâmicos foram pesados secos e úmidos (após 24h de imersão em água). Para completar o ensaio se fez 
necessário a pesagem dos corpos de prova imersos em água. Para o cálculo da porosidade aparente, foram utilizadas equações seguindo também as normas acima citadas.

\subsection{Ensaio Térmico}

Após a preparação dos corpos de prova, montou-se o sistema de testes (caixa) para a realização dos ensaios térmicos. Para tal, fez-se uso de um termômetro digital portátil (termopar) e da estrutura em forma de caixa confeccionada com materiais compósitos de $75 \%$ argila vermelha (matriz), $20 \%$ de pó de vidro (reforço) e $5 \%$ de pó de fumo (reforço). Dentro do sistema foram colocados $4 \mathrm{~L}$ de água (para o total preenchimento deste), com temperatura próxima aos $80^{\circ} \mathrm{C}$ e um sensor acoplado ao termômetro digital portátil, para que assim fossem verificadas as temperaturas da estrutura em intervalos de 5 minutos durante uma hora. Salienta-se que este ensaio foi realizado em triplicada. Em última fase, foi realizado o ensaio térmico de doze horas, o qual simula o período com ausência de sol.

\section{RESULTADOS}

\subsection{Propriedades Mecânicas e físicas dos corpos de prova cerâmicos}

\subsubsection{Flexão em 4 pontos}

Os gráficos abaixo, detalhados nas Figuras 2 e 3, mostram os valores médios do ensaio de flexão em 4 pontos.

Figura 2: Valores médios encontrados no ensaio de força máxima

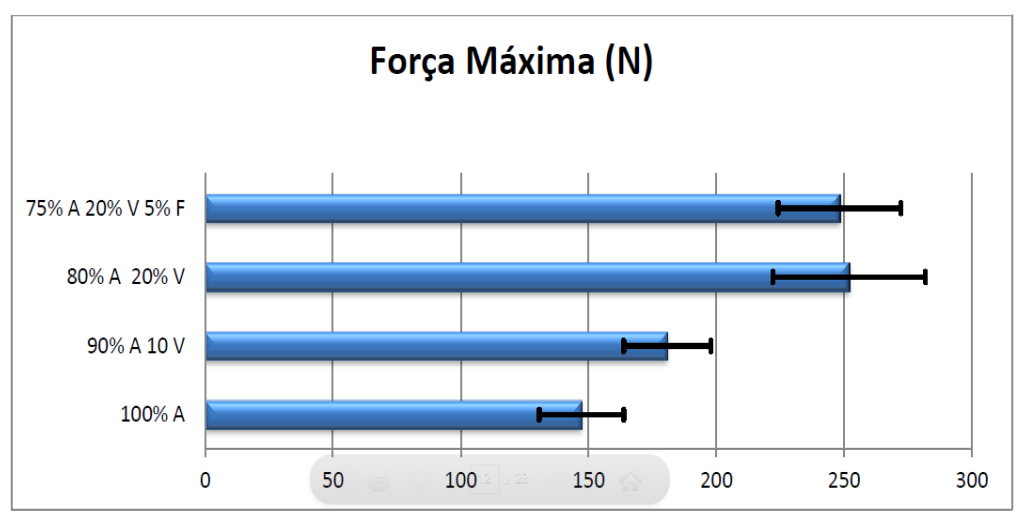


Figura 3: Valores médios encontrados no ensaio de tensão máxima

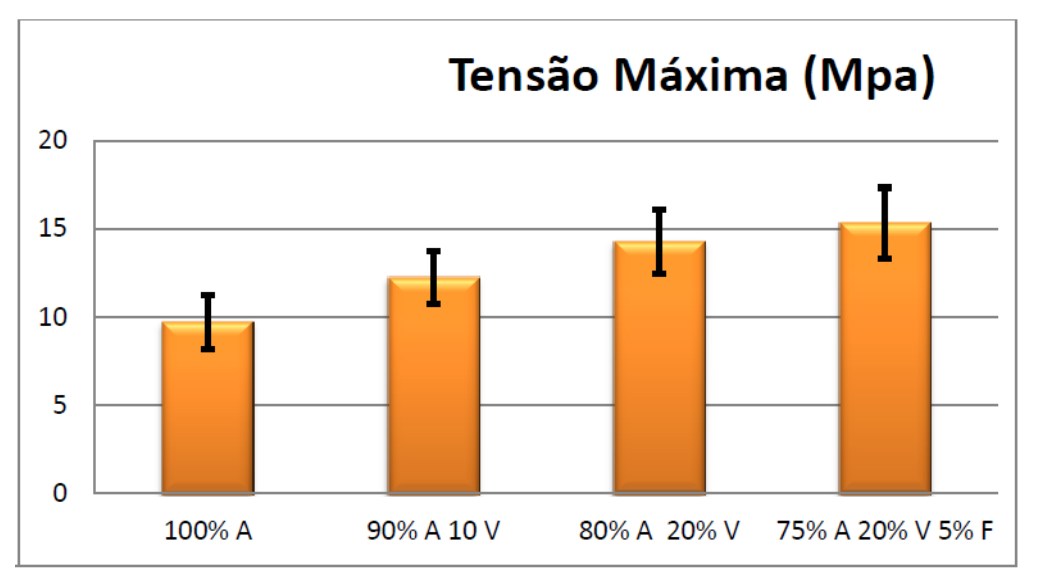

Através dos gráficos, pode-se perceber um aumento da resistência mecânica nos corpos de prova adicionados de vidro, comportamento este esperado em comparação a outras matrizes estudadas, conforme salienta Huang (2010), onde na matriz cimentícia a adição do vidro em concreto auto adensável resulta no aumento da resistência à compressão (até $20 \%$ de utilização). Salienta-se ainda que os corpos de prova com a adição de pó de fumo como reforço tiveram resultados ainda melhores quanto a resistência à compressão, fato este também esperado, pois conforme Okongwu citado por Silva (1988), quando há adição de pequenos teores (3\% e 5\%) obtém-se melhor grau de compactação dos corpos cerâmicos no processo de conformação, melhorando suas propriedades após a queima. Vale lembrar que a porosidade é um fator de relevância quanto à resistência mecânica, visto que os poros são concentradores de microfissuras. Comportamento este observado nas formulações dos corpos de prova, onde os que tiveram adições de pó de vidro sofreram o fenômeno da vitrificação que ocorre após a faixa de $1000^{\circ} \mathrm{C}$ de queima.

\subsubsection{Ensaio de absorção de água}

O gráfico da Figura 5 demonstra os resultados médios de cada formulação de compósitos e o desvio padrão obtidos nos ensaios de absorção de água: 
Figura 5: Valores médios obtidos no ensaio de absorção de água

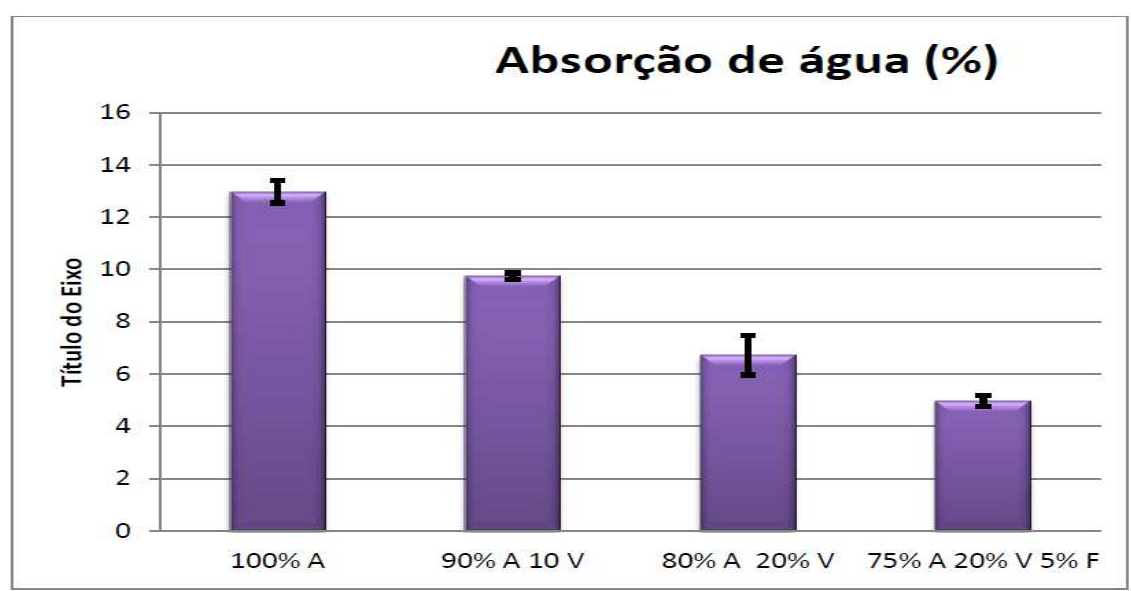

A partir dos dados expostos no gráfico da Figura 3, pôde-se perceber que quanto maior a adição do pó de vidro (reforço), menor a absorção de água e ainda quando adicionado de pó de fumo, o compósito apresentou a menor absorção de todas as formulações. Este fato se deve pela formação de massa vítrea após os $1000^{\circ} \mathrm{C}$ e ainda a sinterização do pó de fumo, pois, após sinterizado (cinza), sua granulometria diminui compactando e conformando o compósito da melhor forma, ou seja, fechando os poros.

\subsubsection{Ensaio de porosidade aparente}

No gráfico da Figura 6 estão dispostos os dados de valores médios e desvio padrão referentes ao ensaio de porosidade aparente:

Figura 6: Valores médios obtidos no ensaio de porosidade aparente

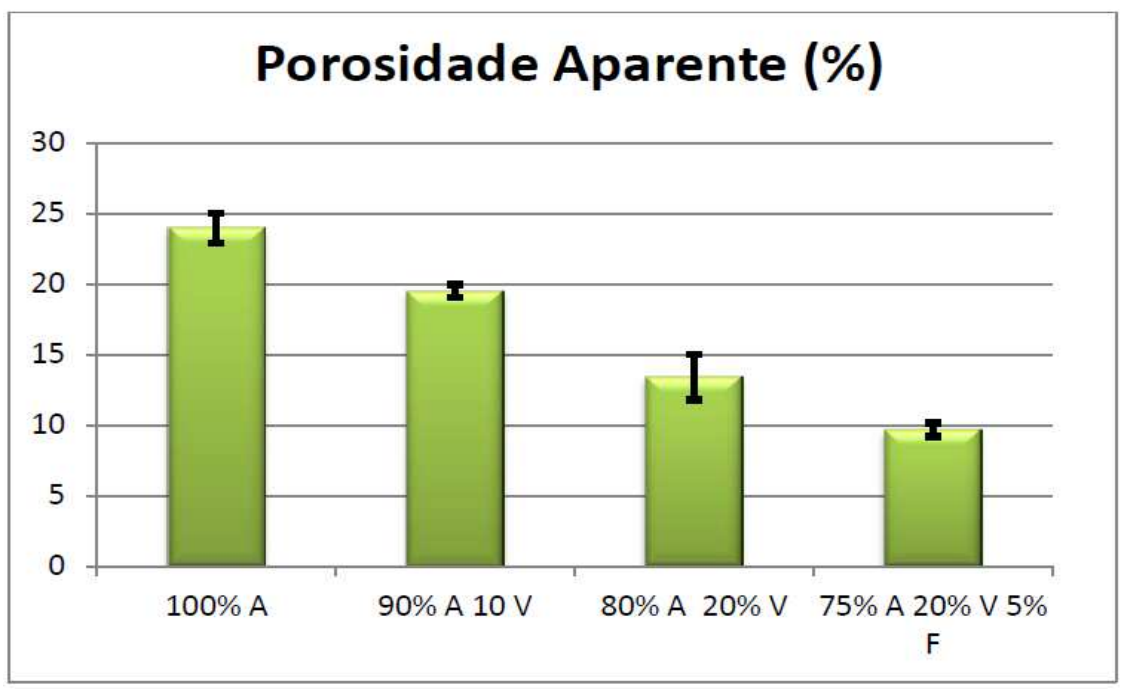


Através dos dados retirados do ensaio de porosidade aparente, pôde-se perceber que a partir da formulação de $75 \%$ argila $20 \%$ pó de vidro e $5 \%$ pó de fumo, obteve-se a menor porosidade aparente. Este fato também está relacionado com a formação da massa vítrea e a temperatura de queima dos corpos de prova (BRAGANÇA, 2002 apud SILVA, 2010). Ainda pôde-se concluir que os corpos de prova adicionados de vidro obtiveram faixas de porosidade aparente dentro dos valores recomendados $(0 \%$ a $20 \%) \mathrm{m} / \mathrm{m}$.

\subsubsection{Ensaio Térmico}

Com base na análise feita a partir dos dados obtidos pelo ensaio térmico, pôde-se constatar que os decréscimos de temperatura foram da ordem de $32^{\circ} \mathrm{C}$, demonstrando eficiência do isolante térmico.

Após o ensaio final de uma hora, foi realizado o ensaio de simulação do período sem a presença do sol. As temperaturas iniciais e finais obtidas foram de, respectivamente $77,8^{\circ} \mathrm{C}$ e $30,3^{\circ} \mathrm{C}$, resultados estes de grande valia, pois quando comparados a resultados já relatados e publicados, estão na faixa de $37^{\circ} \mathrm{C}$ a $39^{\circ} \mathrm{C}$, salientando ainda que a temperatura ótima para o banho é de $38^{\circ} \mathrm{C}$. Vale lembrar também que o volume de água utilizado nos ensaios de bancada é de menor proporção de um industrial que varia 100 até 1000 litros comumente, mostrando mais uma vez o ótimo resultado encontrado por este projeto. O gráfico a seguir demonstra os valores de decréscimo de temperatura por tempo obtidos a partir do ensaio térmico.

Figura 7: Valores de decréscimo de temperatura verificados no ensaio térmico

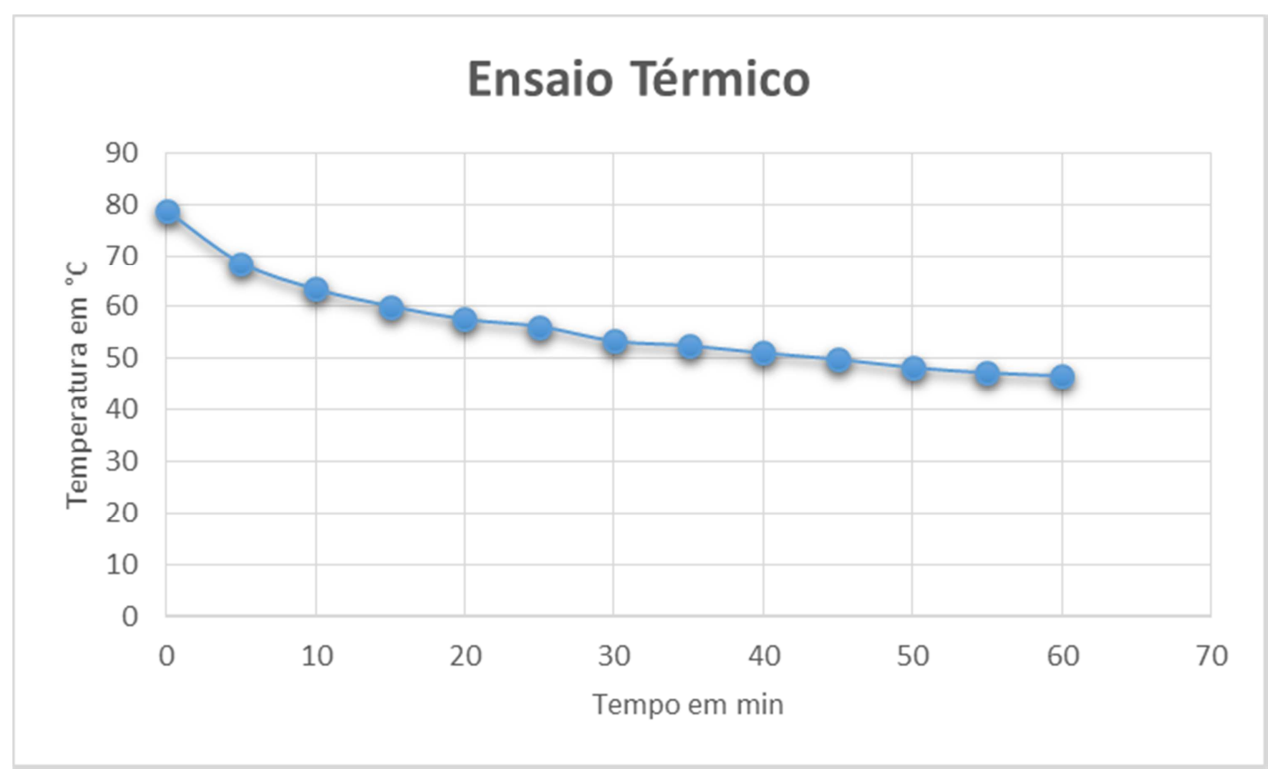




\section{CONSIDERAÇÕES FINAIS}

O emprego de materiais compósitos em matriz cerâmica na confecção de um isolante térmico para sistemas de aquecimento de água demonstra grande valia, uma vez que, além de ser um material que apresenta ótimos índices de isolamento, como descrito no presente trabalho, apresentou índices de propriedades físicas e mecânicas além do esperado e descrito na literatura.

Estes resultados obtidos revelaram um aumento de 57\% na eficiência mecânica (resistência) no material compósito e isolamento térmico próximo aos materiais utilizados em indústrias deste tipo de equipamento.

Salienta-se também a valia deste trabalho na busca de reciclagem de resíduos sólidos, no desenvolvimento de novos e eficientes materiais. Estes que, por sua vez, quando utilizados em sistemas de aquecimento solar de água, diminuem os impactos ambientais causados tanto na fabricação industrial deste tipo de sistema quanto no próprio consumo de energia para o aquecimento de água.

\section{REFERÊNCIAS}

Associação Brasileira de Normas Técnicas. NBR 13817: placas cerâmicas revestimento classificação. Rio de Janeiro, 1997.

Associação Brasileira de Normas Técnicas. NBR 13818: placas cerâmicas para revestimento - Especificação e métodos de ensaios. Rio de Janeiro, 1997.

Associação Brasileira de Normas Técnicas. NBR 15270-3: Componentes cerâmicos. Parte 3: Blocos cerâmicos para alvenaria estrutural e de vedação - Métodos de ensaio

Associação Brasileira de Normas Técnicas. NBR 15310:2009: Componentes cerâmicos Telhas - Terminologia, requisitos e métodos de ensaio.

MORELLI, A. C.; BALDO, J. B. Barbotinas cerâmicas contendo rejeito de vidro soda cal para maturação em baixa temperatura. Cerâmica Industrial, São Carlos, n. 3, v. 8, p. 42-46, maio/jun. 2003.

MATTEUCCI, F.; DONDI, M.; GUARINI, G. Effect of soda-lime glass on sintering and technological properties of porcelain stoneware tiles. Ceramics International, n. 8, v. 28, p. 873-880, 2002.

DANIEL, I.M.; ISHAI, O. Engineering Mechanics of Composite Materials. Oxford University Press, New York: 1994. 
DOREMUS, R. H. Glass Science. Nova Iorque: Wiley-Interscience, 1973.

MENEZES, R. R.; NEVES, G. de A.; FERREIRA, H. C. O estado da arte sobre o uso de resíduos como matérias-primas cerâmicas alternativas. Revista Brasileira de Engenharia Agrícola e Ambiental, Campina Grande, n. 2, v. 6, p. 303-313, 2002.

SANTIAGO, S. C.; BRAGA, R. M.; FELIPE, R. C. T. S.; FELIPE, R. N. B. Comportamento mecânico do compósito de resina Ortoftálica reforçado com fibra de juta e tratado quimicamente com Hidróxido de Sódio. Revista Tecnologia e Desenvolvimento Sustentável. Vol.3; 2007.

SILVA, P. L. B. Obtenção e caracterização de cerâmica vermelha utilizando na matériaprima resíduo argiloso do rerrefino de óleos minerais. Porto Alegre, 2010. 74 p. Dissertação (Mestrado). Programa de Pós-Graduação em Engenharia de Materiais, UFRGS,,2010.

WANG, H-Y., HUANG, W-L. Durability of self-consolidating concrete using waste LCD glass. Construction and Building Materials, n. 6, v. 24, p. 1008-1013, jun. 2010. 